\title{
Succinate Dehydrogenase Assembly Factor 2, Mitochondrial
}

National Cancer Institute

\section{Source}

National Cancer Institute. Succinate Dehydrogenase Assembly Factor 2, Mitochondrial. NCl Thesaurus. Code C97772.

Succinate dehydrogenase assembly factor 2, mitochondrial (166 aa, $20 \mathrm{kDa}$ ) is encoded by the human SDHAF2 gene. This protein is involved in the regulation of electron transport between succinate and ubiquinone. 